\title{
Dietary carbohydrate intake, glycaemic load, glycaemic index and ovarian cancer risk in African-American women
}

\author{
Bo Qin ${ }^{1 *}$, Patricia G. Moorman ${ }^{2}$, Anthony J. Alberg ${ }^{3}$, Jill S. Barnholtz-Sloan ${ }^{4}$, Melissa Bondy $^{5}$, Michele L. Cote ${ }^{6}$, \\ Ellen Funkhouser ${ }^{7}$, Edward S. Peters ${ }^{8}$, Ann G. Schwartz ${ }^{6}$, Paul Terry ${ }^{9}$, Joellen M. Schildkraut ${ }^{2,10}$ and \\ Elisa V. Bandera ${ }^{1}$ \\ ${ }^{1}$ Department of Population Science, Rutgers Cancer Institute of New Jersey, New Brunswick, NJ 08903, USA \\ ${ }^{2}$ Department of Community and Family Medicine, Duke Cancer Institute, Durbam, NC 27705, USA \\ ${ }^{3}$ Hollings Cancer Center and Department of Public Health Sciences, Medical University of South Carolina, Charleston, SC 29425, USA \\ ${ }^{4}$ Case Comprehensive Cancer Center, Case Western Reserve University School of Medicine, Cleveland, OH 44106, USA \\ ${ }^{5}$ Cancer Prevention and Population Sciences Program, Baylor College of Medicine, Houston, TX 77030, USA \\ ${ }^{6}$ Department of Oncology and the Karmanos Cancer Institute, Population Studies and Disparities Research Program, Wayne \\ State University School of Medicine, Detroit, MI 48201, USA \\ ${ }^{7}$ Division of Preventive Medicine, University of Alabama at Birmingham, Birmingham, AL 35205, USA \\ ${ }^{8}$ Epidemiology Program, Louisiana State University Health Sciences Center School of Public Health, New Orleans, LA 70112, USA \\ ${ }^{9}$ Departments of Public Health and Surgery, University of Tennessee-Knoxville, Knoxville, TN 37996, USA \\ ${ }^{10}$ Department of Public Health Sciences, University of Virginia, Charlottesville, VA 22908, USA
}

(Submitted 29 June 2015 - Final revision received 26 October 2015 - Accepted 4 November 2015 - First published online 16 December 2015 )

\begin{abstract}
Epidemiological evidence regarding the association between carbohydrate intake, glycaemic load (GL) and glycaemic index (GI) and risk of ovarian cancer has been mixed. Little is known about their impact on ovarian cancer risk in African-American women. Associations between carbohydrate quantity and quality and ovarian cancer risk were investigated among 406 cases and 609 controls using data from the African American Cancer Epidemiology Study (AACES). AACES is an ongoing population-based case-control study of ovarian cancer in African-Americans in the USA. Cases were identified through rapid case ascertainment and age- and site-matched controls were identified by random-digit dialling. Dietary information over the year preceding diagnosis or the reference date was obtained using a FFQ. Multivariable logistic regression models were used to estimate odds ratios and $95 \% \mathrm{CI}$ adjusted for covariates. The OR comparing the highest quartile of total carbohydrate intake and total sugar intake $v$. the lowest quartile were 1.57 (95\% CI 1.08, 2.28; $\left.P_{\text {trend }}=0.03\right)$ and 1.61 (95\% CI 1.12, 2.30; $\left.P_{\text {trend }}<0.01\right)$, respectively. A suggestion of an inverse association was found for fibre intake. Higher GL was positively associated with the risk of ovarian cancer (OR 1.18 for each 10 units/4184 kJ (1000 kcal); $95 \%$ CI 1.04, 1.33). No associations were observed for starch or GI. Our findings suggest that high intake of total sugars and GL are associated with greater risk of ovarian cancer in African-American women.
\end{abstract}

Key words: African-American women: Carbohydrate: Glycaemic load: Ovarian cancer: Epidemiology

Ovarian cancer is the leading cause of death from gynaecological cancers in developed counties including the USA ${ }^{(1,2)}$, of which nearly $90 \%$ are epithelial ovarian carcinomas ${ }^{(3)}$. Approximately $10 \%$ of cases are thought to arise from inherited germline mutations while the rest are thought to be sporadic $^{(3)}$. As at present there is no reliable screening available for ovarian cancer, most cases are diagnosed at an advanced stage, with a poor prognosis $^{(4)}$. Moreover, compared with European-Americans, African-American women tend to have a worse 5-year survival rate $^{(5)}$, highlighting a critical need for identifying modifiable preventive factors. However, there is a scarcity of epidemiological studies in this area for African-American women.
Although there are a few established modifiable risk factors for ovarian cancer, the role of diet has been proposed. Carbohydrates in particular have been a focus of research ${ }^{(6)}$, as long-term consumption of high levels of carbohydrates, especially sugars, could plausibly contribute to ovarian carcinogenesis ${ }^{(7,8)}$. The majority of epidemiological studies evaluating associations between intakes of carbohydrate ${ }^{(9-15)}$, total sugars and added sugars $^{(13,15-19)}$ and fibre ${ }^{(9-14,20,21)}$ and ovarian cancer risk have been conducted in European or European-American populations with mixed results. Inconsistencies in findings have been attributed to the different type, amount and rate of digestion of carbohydrates $^{(13)}$. These factors may lead to varied blood glucose

Abbreviations: GI, glycaemic index; GL, glycaemic load; IGF-1, insulin-like growth factor-1.

* Corresponding author: B. Qin, fax +1 732235 8808, email bonnie.qin@rutgers.edu 
and postprandial insulin responses, which have been suggested to play critical roles in ovarian tumour development ${ }^{(13)}$. Therefore, it is necessary to evaluate the impact of both the quality and the quantity of carbohydrate intake on ovarian cancer risk.

Glycaemic index (GI) is a quality measure of carbohydrates, whereas glycaemic load (GL) reflects both the average quality and the quantity of carbohydrates. GI is a numerical index that is defined as the incremental area under the blood glucose response curve after a 50-g carbohydrate intake of a test food relative to an equivalent carbohydrate portion of bread or glucose ${ }^{(22)}$. Through combining the food's GI value and the carbohydrate content of the food's usual serving size, GL reflect the overall effects of a food on postprandial blood glucose concentrations ${ }^{(23)}$. A few studies have evaluated the relation between GL, GI and ovarian cancer risk, and the evidence is mixed ${ }^{(13,15,18,24,25)}$. In three of these studies, positive associations were observed for GL only or both GI and $\mathrm{GL}^{(13,15,25)}$, and were stronger in postmenopausal women ${ }^{(15,25)}$, or overweight and obese women ${ }^{(13)}$. Two other studies found a null relation ${ }^{(18)}$ or an inverse association for $\mathrm{GI}^{(24)}$

Compared with European-Americans, African-Americans have similar total carbohydrate intake, but tend to have lower fibre consumption and higher intake of total sugars and added sugars $^{(26-28)}$. Fibre intake has been hypothesised to be beneficial for ovarian cancer prevention, whereas sugar intake is suggested to play the opposite role ${ }^{(16,20)}$. Furthermore, there are important differences in the physiology of glucose homoeostasis between African-Americans and European-Americans, with higher insulin secretion and more insulin resistance in African-Americans ${ }^{(29,30)}$. Therefore, our study aimed to examine the associations between types of carbohydrate intake, GL and GI and ovarian cancer risk in African-American women. We specifically examined whether associations may be stronger in postmenopausal or overweight/ obese women based on previous findings ${ }^{(13,15,25)}$, and assessed whether there might be greater associations among diabetics as they may suffer from long-term higher insulin response to carbohydrate intake $^{(8)}$. As some studies have suggested differences in ovarian cancer risk factors by histological subtypes ${ }^{(31,32)}$, we also proposed to examine these associations by ovarian cancer subtypes (serous $v$. non-serous). To our knowledge, this is the first study that has examined the association between carbohydrate quality and quantity and ovarian cancer risk in African-Americans.

\section{Methods}

\section{Study population}

The African American Cancer Epidemiology Study (AACES) has been described in detail elsewhere ${ }^{(33)}$. In brief, AACES is an ongoing population-based case-control study of ovarian cancer in African-American women in eleven sites in the USA (Alabama, Georgia, Illinois, Louisiana, Michigan, North Carolina, New Jersey, Ohio, South Carolina, Tennessee and Texas). Cases were identified by rapid case ascertainment utilising state cancer registries, SEER (Surveillance, Epidemiology and End Results) registries or via hospitals' gynaecological oncology departments. Eligible cases included all self-identified African-American women aged between 20 and 79 years, with newly diagnosed, histologically confirmed invasive epithelial ovarian cancer. Controls who self-identified as
African-American were selected using random-digit dialling and were matched to cases by 5 -year age groups and state of residence. Women who had a previous history of ovarian cancer or a bilateral oophorectomy were ineligible controls. Only women able to complete an interview in English were eligible to participate. Among those who could be contacted, $66.5 \%$ of potential cases and $72 \%$ of potential controls agreed to participate in the main telephone interview ${ }^{(33)}$. The present study was approved by the Institutional Review Boards at all study sites.

We used data from AACES participants recruited from December 2010 to December 2014, which included 495 cases and 711 controls. Among them, 421 cases (85\%) and 635 controls (89\%) completed the FFQ for dietary assessment. We compared characteristics of women completing and not completing the FFQ and found no difference with respect to age, education, region, BMI and smoking status (results not shown). Participants were excluded from the analysis if they reported an extreme energy intake defined as greater than twice the interquartile range of the log energy intake (case, $n 1$; control, $n 3$ ) or if they were missing important covariates (case, $n$ 14; control, $n$ 23), such as tubal ligation and family history of ovarian/breast cancer. The final analytical sample comprised 406 cases and 609 controls.

\section{Data collection}

Upon signing informed consent, participants completed a computer-assisted telephone interview. The questionnaire included detailed questions on demographic information, personal and family history of cancer, reproductive history, medication use, lifestyle characteristics and other factors of particular relevance to African-American women such as perceived discrimination, access to healthcare facilities and cultural beliefs.

Dietary intake was assessed using a self-administered Block 2005 FFQ, which included questions on frequency and portion size on 110 food items. The FFQ was mailed to participants with portion size pictures to facilitate recall. Participants were asked to estimate their usual consumption of each of these food items during the year before their reference date. Nutrient intakes were derived from the FFQ through the Block Dietary Data Systems based on the US Department of Agriculture (USDA) Food and Nutrient Database for Dietary Studies, version 1.0. The validity of the Block FFQ has been evaluated ${ }^{(34,35)}$. The correlations between estimates from the questionnaire and $2-\mathrm{d}$ food records were $>0.50$ for most nutrients. In particular, the correlation of energy-adjusted carbohydrate intake was 0.60 and 0.61 , respectively, for women below or above age 65 years ${ }^{(35)}$. Total carbohydrate values consist of total sugars (including added sugars), starch and fibre intakes.

The GI and GL values for food items in our study were based on the published international tables of values ${ }^{(36)}$, or from direct testing of food items at the University of North Carolina Nutrition Obesity Research Center, using glucose as the reference. The GL value of each food was calculated by multiplying the non-fibre carbohydrate contained in a specified serving size of the food by the GI value of that food, divided by 100 . The daily GL value of each individual was the sum of all foods after multiplying the GL of each food by its frequency of consumption and portion size. An individual's daily GI value was determined by dividing the daily GL by the total amount of non-fibre carbohydrate consumed. 
Top food sources that contribute to carbohydrates, sugars or GL in this sample are provided in online Supplementary Table S1.

\section{Statistical analysis}

Distributions of demographic and major risk factors for ovarian cancer, such as parity and tubal ligation, were compared between cases and controls using $\chi^{2}$ tests. Student's $t$ tests were used to compare the mean nutrient intakes by cases and controls.

Dietary variables under investigation - total carbohydrate, total sugars, added sugars, starch, fibre and GL, except GI - were adjusted for energy intake using the multivariate nutrient density approach $^{(37)}$. Dietary variables were then categorised into quartiles based on the distributions among controls. Unconditional logistic regression models were used to calculate OR and 95\% CI for ovarian cancer risk by levels of energy-adjusted dietary intake. Linear trends were tested by modelling the median value of each quartile as a continuous variable. Dietary variables were also evaluated as a continuous increment based on the difference between the 75th and 25th percentile of the controls' distribution, rounded to one significant digit.

The first model adjusted for age, geographic region (south- and mid-Atlantic, south central, Midwest), education (high school or less, some post-high school training, college or graduate degree) and total energy intake ${ }^{(38)}$. Additional covariates selected for model 2 included risk factors for ovarian cancer that changed the effect estimate of each corresponding dietary variable by $>10 \%$ : parity $(0,1-2,>2)$, oral contraceptive use (never, $<60, \geq 60$ months), menopause status (pre-, postmenopause), tubal ligation (no, yes) and first-degree family history of breast/ovarian cancer (no, yes). The second model additionally adjusted for vegetable consumption (servings, continuous) or alcohol consumption (drink-equivalent, continuous) when evaluating added sugars or fibre, respectively. As vegetable intake is an important source of fibre and affects GL and GI values, we did not adjust for vegetable consumption when evaluating their associations with ovarian cancer to avoid over-adjustment. Other potential confounders considered were age at menarche ( $<12,12-13,>13$ years), hormone therapy use (never, ever) and smoking (never, ever), but were not included in the final model as they did not change the effect estimate by $10 \%$.

Further analyses were conducted adjusting for BMI and diabetes, both of which may be either confounders or mediators in the causal pathway between carbohydrate intake and ovarian cancer. We also considered possible confounding effects by total sugars and added sugars when evaluating fibre intake and SFA and total fat intake as potential covariates for any of the associations under study.

We examined whether the associations were modified by menopausal status, obesity and diabetes by testing statistical interactions using product terms with the continuous variable of dietary intake. We also examined whether the associations were different by histological subtypes of ovarian cancer. As smoking may be related to mucinous tumours ${ }^{(39)}$, we further adjusted for smoking when examining the associations by histological subtypes. A $P$ value $<0 \cdot 1$ was defined as statistically significant for interaction, whereas $P<0.05$ was used for main effects. All the statistical analyses mentioned above were performed using STATA (version 11.2; StataCorp LP). We had excellent power for main analyses evaluating carbohydrate intake, GL, GI and ovarian cancer risk. As assessed by Epi Info (version 7.1.5), we could detect an OR of 1.49 using quartile exposures based on a power of $80 \%$ and two-sided $95 \%$ CI.

\section{Results}

Compared with controls, cases were slightly older (cases mean 57.5 years $v$. controls 54.5 years; $P$ value 0.01 ), less likely to reside in the Midwest, to have children, to have used oral contraceptives or have had a tubal ligation (Table 1). Cases were more likely to have a family history of breast/ovarian cancer. Cases were similar to controls in total energy intake and energy-adjusted total and SFA intake. They had statistically significant higher intakes of carbohydrate, total sugars, fructose and added sugars, higher GL and lower protein intake and alcohol consumption, although the magnitude of difference was very small for carbohydrate or protein intakes comparing cases and controls (Table 2).

As shown in Table 3, total carbohydrate intake was strongly positively associated with ovarian cancer risk. The multivariable-adjusted OR comparing the highest $v$. the lowest quartile of total carbohydrate intake was 1.57 (95\% CI 1.08 , $\left.2 \cdot 28 ; P_{\text {trend }}=0.03\right)$. In continuous analyses, we estimated a $32 \%$ increase in OR (95\% CI 1.09, 1.61) per $30 \mathrm{~g} / 4184 \mathrm{~kJ}(1000 \mathrm{kcal})$ of carbohydrate consumption. The positive association between carbohydrate intake and ovarian cancer risk seemed to be attributable to total sugar intake, with an OR of 1.61 (95\% CI $1.12,2.30$; $\left.P_{\text {trend }}<0.01\right)$ for those in the highest quartile compared with the lowest. Each additional $20 \mathrm{~g} / 4184 \mathrm{~kJ}(1000 \mathrm{kcal})$ per d of sugar intake was associated with a $22 \%$ increased OR (95\% CI 1.08, 1.37). For a $8368 \mathrm{~kJ}(2000 \mathrm{kcal})$ diet, such an increment represents approximately a can of soda or one cup of ice-cream. When further evaluating types of sugars, we observed that fructose intake was positively associated with the risk of ovarian cancer (OR 1.23 for each $10 \mathrm{~g} / 4184 \mathrm{~kJ}$ (1000 kcal); $95 \%$ CI 1.05, 1.43). Added sugar intake was positively associated with ovarian cancer risk but was not statistically significant. We did not find an association between starch intake and ovarian cancer risk. There was a suggestion of decreased risk for higher total fibre intake but the risk estimate was only significant for the third quartile compared with the lowest. A post hoc analysis that evaluated fibre from various sources (from vegetable and fruit, from beans, from grains) as either quartiles or continuous variables did not find any association, except a marginally significant $12 \%$ decrease in the OR (95\% CI $0.74,0.99)$ per $3 \mathrm{~g} / 4184 \mathrm{~kJ}(1000 \mathrm{kcal})$ of fibre from vegetable and fruit sources (data not shown).

We found a positive linear association between GL and ovarian cancer risk (OR 1.18 for each 10 units/4184 kJ (1000 kcal); $95 \%$ CI $1 \cdot 04,1 \cdot 33)$. However, we only observed a significant association when comparing the third quartile $v$. the lowest (OR 1.57; $95 \% \mathrm{CI}$ $1.09,2.28$ ) but not for the highest quartile of GL. There was no evidence of an association between GI and ovarian cancer, with OR near the null and not statistically significant.

Our results were not materially altered with further adjustment for BMI or diabetes. Results for fibre were not altered after adjusting for total or added sugar intake. 
Table 1. Descriptive characteristics of African-American women with and without ovarian cancer, African American Cancer Epidemiology Study 2010-2014 (Number and percentages)

\begin{tabular}{|c|c|c|c|c|c|}
\hline \multirow[b]{2}{*}{ Variables } & \multicolumn{2}{|c|}{ Cases ( $n$ 406) } & \multicolumn{2}{|c|}{ Controls ( $n$ 609) } & \multirow[b]{2}{*}{$P^{*}$} \\
\hline & $n$ & $\%$ & $n$ & $\%$ & \\
\hline \multicolumn{6}{|l|}{ Age (years) } \\
\hline$<50$ & 88 & $21 \cdot 7$ & 172 & $28 \cdot 2$ & \multirow[t]{3}{*}{0.01} \\
\hline $50-59$ & 146 & $36 \cdot 0$ & 230 & 37.8 & \\
\hline$\geq 60$ & 172 & $42 \cdot 4$ & 207 & 34.0 & \\
\hline \multicolumn{6}{|l|}{ Education } \\
\hline High school or less & 180 & $44 \cdot 3$ & 224 & $36 \cdot 8$ & \multirow[t]{3}{*}{0.06} \\
\hline Some post-high school training & 131 & $32 \cdot 3$ & 222 & $36 \cdot 5$ & \\
\hline College or graduate degree & 95 & 23.4 & 163 & $26 \cdot 8$ & \\
\hline \multicolumn{6}{|l|}{ Regiont } \\
\hline South- and mid-Atlantic & 228 & $56 \cdot 2$ & 321 & $52 \cdot 7$ & \multirow[t]{3}{*}{0.02} \\
\hline South central & 109 & $26 \cdot 9$ & 141 & 23.2 & \\
\hline Midwest & 69 & $17 \cdot 0$ & 147 & $24 \cdot 1$ & \\
\hline \multicolumn{6}{|l|}{ Parity } \\
\hline 0 & 79 & $19 \cdot 5$ & 80 & $13 \cdot 1$ & \multirow[t]{3}{*}{0.02} \\
\hline $1-2$ & 177 & $43 \cdot 6$ & 273 & $44 \cdot 8$ & \\
\hline$>2$ & 150 & $37 \cdot 0$ & 256 & $42 \cdot 0$ & \\
\hline \multicolumn{6}{|l|}{ Oral contraceptive use } \\
\hline Never & 116 & 28.6 & 118 & $19 \cdot 4$ & \multirow[t]{3}{*}{$<0.01$} \\
\hline$<60$ months & 163 & $40 \cdot 2$ & 275 & $45 \cdot 2$ & \\
\hline$\geq 60$ months & 127 & $31 \cdot 3$ & 216 & $35 . \overline{5}$ & \\
\hline \multicolumn{6}{|c|}{ Use of hormone-replacement therapy among postmenopausal women } \\
\hline Never & 219 & 74.5 & 321 & $76 \cdot 8$ & \multirow[t]{2}{*}{0.48} \\
\hline Ever & 75 & $25 \cdot 5$ & 97 & $23 \cdot 2$ & \\
\hline \multicolumn{6}{|l|}{ Age at menarche (years) } \\
\hline$<12$ & 90 & $22 \cdot 2$ & 165 & $27 \cdot 1$ & \multirow[t]{3}{*}{0.21} \\
\hline $12-13$ & 212 & $52 \cdot 2$ & 300 & $49 \cdot 3$ & \\
\hline$>13$ & 104 & 25.6 & 144 & 23.7 & \\
\hline \multicolumn{6}{|l|}{ Menopause status } \\
\hline Premenopausal & 109 & $26 \cdot 9$ & 189 & 31.0 & \multirow[t]{2}{*}{0.15} \\
\hline Postmenopausal & 297 & 73.2 & 420 & $69 \cdot 0$ & \\
\hline \multicolumn{6}{|l|}{ Tubal ligation } \\
\hline No & 271 & $66 \cdot 8$ & 364 & $59 \cdot 8$ & \multirow[t]{2}{*}{0.02} \\
\hline Yes & 135 & $33 \cdot 3$ & 245 & $40 \cdot 2$ & \\
\hline Family history of breast/ovarian ca & & & & & \\
\hline No & 297 & $73 \cdot 2$ & 494 & $81 \cdot 1$ & $<0.01$ \\
\hline Yes & 109 & $26 \cdot 9$ & 115 & $18 \cdot 9$ & \\
\hline Diabetes & & & & & \\
\hline No & 318 & $78 \cdot 3$ & 468 & $76 \cdot 9$ & 0.58 \\
\hline Yes & 88 & $21 \cdot 7$ & 141 & 23.2 & \\
\hline BMI 1 year before $\left(\mathrm{kg} / \mathrm{m}^{2}\right) \ddagger$ & & & & & \\
\hline$<25$ & 54 & $13 \cdot 3$ & 108 & $17 \cdot 7$ & 0.17 \\
\hline $25-<30$ & 106 & $26 \cdot 1$ & 151 & $24 \cdot 8$ & \\
\hline$\geq 30$ & 246 & $60 \cdot 6$ & 350 & 57.5 & \\
\hline Smoking & & & & & \\
\hline Never & 231 & $56 \cdot 9$ & 349 & $57 \cdot 3$ & 0.90 \\
\hline Current/former & 175 & $43 \cdot 1$ & 260 & $42 \cdot 7$ & \\
\hline
\end{tabular}

* $\chi^{2}$ tests.

† South- and mid-Atlantic includes Georgia, North Carolina, New Jersey, South Carolina; South central includes Alabama, Louisiana, Tennessee, Texas; and Midwest includes Illinois, Michigan, Ohio.

$\ddagger 1$ year before diagnosis (cases)/interview (controls)

Estimates for total carbohydrates, total sugars and GL were strengthened after adjusting for total fat or SFA intake (online Supplementary Table S2), although the interpretation should be cautious as this isoenergetic model estimates the effect of substituting carbohydrates for the same amount of non-fat sources of energy. Results for added sugars, fibre or GI remained unchanged.

Results for carbohydrate intake, GL and GI as continuous variables were stratified by diabetes status in addition to interaction tests as the number of women with diabetes was small (online Supplementary Table S3). Although interaction tests were not statistically significant, the positive association between carbohydrate intake, total sugars, added sugars and GL with ovarian cancer risk appeared to be stronger among participants with diabetes. We also evaluated effect modification by menopausal status and BMI. No significant interaction was found. Associations were also evaluated by histological subtype. Given the small number of non-serous subtypes, they were combined for analysis. The findings did not seem to be different for serous $v$. non-serous subtypes of ovarian cancer (data not shown). Further adjusting for smoking did not alter this result. 
Table 2. Energy-adjusted dietary factors of African-American women with and without ovarian cancer, African American Cancer Epidemiology Study 2010-2014* (Mean values and standard deviations)

\begin{tabular}{|c|c|c|c|c|c|}
\hline \multirow[b]{2}{*}{ Daily nutrient intakes } & \multicolumn{2}{|c|}{ Cases $(n$ 406) } & \multicolumn{2}{|c|}{ Controls ( $n$ 609) } & \multirow[b]{2}{*}{$P \dagger$} \\
\hline & Mean & SD & Mean & SD & \\
\hline Total energy intake (kJ) & $7472 \cdot 6$ & $5107 \cdot 8$ & $7275 \cdot 9$ & $4609 \cdot 5$ & 0.44 \\
\hline Total energy intake (kcal) & $1795 \cdot 9$ & $1220 \cdot 8$ & $1739 \cdot 0$ & $1101 \cdot 7$ & \\
\hline Total carbohydrate (g/4184 kJ (1000 kcal)) & $122 \cdot 8$ & $19 \cdot 6$ & $119 \cdot 6$ & $20 \cdot 2$ & 0.01 \\
\hline Total sugars $(\mathrm{g} / 4184 \mathrm{~kJ}(1000 \mathrm{kcal}))$ & $65 \cdot 4$ & $22 \cdot 2$ & $61 \cdot 5$ & $20 \cdot 6$ & 0.005 \\
\hline Fructose $(\mathrm{g} / 4184 \mathrm{~kJ}(1000 \mathrm{kcal}))$ & $17 \cdot 2$ & $8 \cdot 8$ & $16 \cdot 0$ & $8 \cdot 2$ & 0.03 \\
\hline Sucrose (g/4184 kJ (1000 kcal)) & $23 \cdot 0$ & $11 \cdot 4$ & $22 \cdot 1$ & $11 \cdot 8$ & 0.23 \\
\hline Added sugars (tsp/4184 kJ (1000 kcal)) & $9 \cdot 0$ & 4.5 & 8.5 & $4 \cdot 3$ & 0.04 \\
\hline Starch $(g / 4184 \mathrm{~kJ}(1000 \mathrm{kcal}))$ & $48 \cdot 5$ & $10 \cdot 3$ & 48.9 & $10 \cdot 7$ & 0.55 \\
\hline Fibre (g/4184 kJ (1000 kcal)) & $8 \cdot 9$ & $3 \cdot 6$ & $9 \cdot 1$ & 3.9 & 0.31 \\
\hline Glycaemic load (units/4184 kJ (1000 kcal)) & $59 \cdot 4$ & $10 \cdot 3$ & $57 \cdot 6$ & $11 \cdot 3$ & 0.01 \\
\hline Glycaemic index (units) & $52 \cdot 2$ & $3 \cdot 7$ & $52 \cdot 1$ & 4.0 & 0.60 \\
\hline Total fat (g/4184 kJ (1000 kcal)) & 41.5 & $6 \cdot 5$ & 41.7 & $6 \cdot 7$ & 0.67 \\
\hline SFA (g/4184 kJ (1000 kcal)) & $12 \cdot 3$ & 2.5 & $12 \cdot 3$ & 2.5 & 0.86 \\
\hline Protein (g/4184 kJ (1000 kcal)) & $37 \cdot 0$ & $7 \cdot 7$ & $37 \cdot 9$ & $8 \cdot 2$ & 0.05 \\
\hline Alcohol, drink-equivalent & 0.30 & 0.07 & 0.47 & 0.05 & 0.05 \\
\hline
\end{tabular}

Tsp, teaspoon.

* Glycaemic index and alcohol intake is not further energy adjusted.

$\dagger$ Student's $t$ test.

$\ddagger$ One drink equivalent is defined as $12 \mathrm{fl} \mathrm{oz}$ of beer, $5 \mathrm{fl} \mathrm{oz}$ of wine or $1.5 \mathrm{fl} \mathrm{oz}$ of distilled spirits.

\section{Discussion}

In this first population-based study of carbohydrate intake and ovarian cancer risk in African-American women, we observed that high carbohydrate and sugar intakes were associated with a greater risk of ovarian cancer, independent of several relevant non-dietary and dietary factors. There was also a suggestion of a positive association between GL and ovarian cancer risk. The association between carbohydrate intake, sugar (total and added) intakes or GL and ovarian cancer appeared to be stronger for women with diabetes, although the interaction tests were not statistically significant.

Total carbohydrate intake is a combination of sugars, starch and fibre consumption. Our results suggested that the positive association between carbohydrate intake and ovarian cancer risk was primarily driven by sugar intake. In support of our findings, a previous study found that higher consumption of bread, pasta and rice and more total sugar intakes were associated with an increased risk of ovarian cancer ${ }^{(16)}$. However, other studies reported an inverse association $^{(19)}$ or no association between sugar intake and ovarian cancer risk ${ }^{(13,15,17,18)}$.

The inconsistencies in findings between our study and most of the previous studies, which were mainly conducted in European or European-American women, may be due to differences in consumption of sugar types or glucose metabolism of African-Americans. Although the range of carbohydrate and total sugar intake in our study is comparable with those reported in other studies ${ }^{(19)}$, the differences in the intake of sugar subtypes have been noticed comparing African-Americans and European-Americans. According to the National Health and Nutrition Examination Survey III, African-Americans have a higher consumption of fructose compared with non-Hispanic whites ${ }^{(40)}$. Evidence is accumulating that compared with other sugars, fructose is more involved in the development of insulin resistance $^{(41)}$, a hypothesised mechanism for ovarian cancer ${ }^{(42)}$.
Consistently, we found a positive association between fructose consumption and ovarian cancer risk. Furthermore, AfricanAmericans are more hyperinsulinaemic and insulin resistant compared with European-Americans ${ }^{(30)}$, suggesting that they may have a higher ovarian cancer risk for a given amount of sugar intake. Another reason to explain the inconsistent findings may be due to the different energy-adjustment methods. It was suggested that the nutrient density method as used in our study, or residual method, may be more powerful than the standard energy-adjustment model employed in most of the previous studies $^{(13,15,18)}$ to detect the relative odds when the nutrient variables were categorised ${ }^{(43)}$.

The evidence regarding the association between fibre intake and ovarian cancer risk has been inconsistent. Although some studies found no association between fibre intake and the risk of ovarian cancer $^{(10,14,21,44)}$, others found an inverse association ${ }^{(9,11-13,20)}$. Two of these studies further examined types of fibre intake and showed that the inverse association was observed only for vegetable fibre but not for fruit or cereal fibre ${ }^{(11,20)}$. Our data, which observed an inverse association with dietary fibre from vegetable and fruit but not with fibre from grains, support the fact that the effects of dietary fibre on ovarian cancer may vary depending on the food sources.

Among the few previous studies examining the associations of GL and GI with ovarian cancer risk ${ }^{(13,15,18,24,25)}$, our results are consistent with those of a prospective cohort study and a population-based case-control study that showed positive associations with GL but not with $\mathrm{GI}^{(13,15)}$. The null findings with GI suggested that it may not be as good as GL to reflect the overall glycaemic effect of the diet, as GL also takes the amount of carbohydrate intake into consideration in addition to carbohydrate quality as for $\mathrm{GI}^{(24)}$.

Potential mechanisms linking carbohydrate-rich foods to ovarian tumour development have been proposed. Long-term consumption of carbohydrate-rich foods can result in chronic hyperinsulinaemia, which can indirectly promote the production 
Table 3. Association between daily dietary carbohydrate intake and ovarian cancer risk in African American Cancer Epidemiology Study 2010-2014 (Numbers and percentages; odds ratios and $95 \%$ confidence intervals)

\begin{tabular}{|c|c|c|c|c|c|c|c|c|}
\hline & \multicolumn{2}{|c|}{ Cases (n 406) } & \multicolumn{2}{|c|}{ Controls (n 609) } & \multicolumn{2}{|c|}{ Model $1^{*}$} & \multicolumn{2}{|c|}{ Model 2† } \\
\hline & $n$ & $\%$ & $n$ & $\%$ & OR & $95 \% \mathrm{Cl}$ & OR & $95 \% \mathrm{Cl}$ \\
\hline \multicolumn{9}{|c|}{ Total carbohydrate (g/4184 kJ (1000 kcal)) } \\
\hline Q1 $(\leq 106.9)$ & 83 & $20 \cdot 4$ & 153 & $25 \cdot 1$ & $1 \cdot 00$ & Ref. & $1 \cdot 00$ & Ref. \\
\hline Q2 (107.0-120.1) & 105 & $25 \cdot 9$ & 153 & $25 \cdot 1$ & $1 \cdot 31$ & $0.90,1.90$ & $1 \cdot 32$ & $0.90,1.92$ \\
\hline Q3 $(120 \cdot 2-133 \cdot 1)$ & 97 & 23.9 & 152 & $25 \cdot 0$ & $1 \cdot 18$ & $0.81,1.73$ & $1 \cdot 17$ & $0.80,1.72$ \\
\hline Q4 $(\geq 133 \cdot 2)$ & 121 & $29 \cdot 8$ & 151 & $24 \cdot 8$ & $1 \cdot 58$ & $\begin{array}{l}1 \cdot 10,2 \cdot 28 \\
0.03\end{array}$ & $1 \cdot 57$ & $\begin{array}{l}1.08,2.28 \\
0.03\end{array}$ \\
\hline Per $30 \mathrm{~g} / 4184 \mathrm{~kJ}(1000 \mathrm{kcal}) \ddagger$ & & & & & $1 \cdot 33$ & $1.09,1.61$ & $1 \cdot 32$ & $1.09,1.61$ \\
\hline \multicolumn{9}{|l|}{ Total sugars (g/4184 kJ (1000 kcal)) } \\
\hline Q1 $(\leq 48 \cdot 2)$ & 92 & $22 \cdot 7$ & 153 & $25 \cdot 1$ & 1.00 & Ref. & 1.00 & Ref. \\
\hline Q2 (48.3-60.9) & 96 & $23 \cdot 7$ & 152 & $25 \cdot 0$ & 1.04 & $0.72,1.51$ & $1 \cdot 03$ & $0.70,1.50$ \\
\hline Q3 (61.0-72.7) & 81 & $20 \cdot 0$ & 152 & $25 \cdot 0$ & 0.91 & $0.62,1.33$ & 0.90 & $0.61,1.33$ \\
\hline Q4 $(\geq 72 \cdot 8)$ & 137 & 33.7 & 152 & $25 \cdot 0$ & 1.57 & $1 \cdot 11,2.24$ & 1.61 & $1 \cdot 12,2 \cdot 30$ \\
\hline$P_{\text {trend }}$ & & & & & & 0.01 & & $<0.01$ \\
\hline Per 20 g/4184 kJ (1000 kcal)‡ & & & & & $1 \cdot 21$ & $1.08,1.37$ & $1 \cdot 22$ & $1.08,1.37$ \\
\hline \multicolumn{9}{|l|}{ Fructose } \\
\hline Q1 $(\leq 10 \cdot 1)$ & 89 & $21 \cdot 9$ & 153 & $25 \cdot 1$ & 1.00 & Ref. & $1 \cdot 00$ & Ref. \\
\hline Q2 (10.2-14.8) & 98 & $24 \cdot 1$ & 153 & $25 \cdot 1$ & $1 \cdot 14$ & $0.79,1.65$ & $1 \cdot 10$ & $0.76,1.61$ \\
\hline Q3 (14.9-20.0) & 102 & $25 \cdot 1$ & 151 & $24 \cdot 8$ & $1 \cdot 20$ & $0.83,1.74$ & $1 \cdot 16$ & $0.79,1.68$ \\
\hline Q4 $(\geq 20 \cdot 1)$ & 117 & $28 \cdot 8$ & 152 & $25 \cdot 0$ & 1.42 & $0.99,2.03$ & 1.42 & $0.98,2.05$ \\
\hline$P_{\text {trend }}$ & & & & & & 0.06 & & 0.06 \\
\hline Per 10 g/4184 kJ (1000 kcal)‡ & & & & & $1 \cdot 23$ & $1.05,1.43$ & $1 \cdot 23$ & $1.05,1.43$ \\
\hline \multicolumn{9}{|l|}{ Sucrose } \\
\hline Q1 $(\leq 14 \cdot 0)$ & 78 & $19 \cdot 2$ & 153 & $25 \cdot 1$ & $1 \cdot 00$ & Ref. & $1 \cdot 00$ & Ref. \\
\hline Q2 (14.1-19.9) & 116 & $28 \cdot 6$ & 152 & $25 \cdot 0$ & $1 \cdot 53$ & $1 \cdot 05,2 \cdot 22$ & $1 \cdot 51$ & $1.03,2.21$ \\
\hline Q3 (20.0-27.5) & 105 & $25 \cdot 9$ & 152 & $25 \cdot 0$ & $1 \cdot 38$ & $0.94,2.02$ & $1 \cdot 33$ & $0.90,1.96$ \\
\hline Q4 $(\geq 27 \cdot 6)$ & 107 & $26 \cdot 4$ & 152 & $25 \cdot 0$ & $1 \cdot 37$ & $0.94,1.99$ & 1.39 & $0.95,2.04$ \\
\hline$P_{\text {trend }}$ & & & & & & 0.28 & & 0.24 \\
\hline Per $10 \mathrm{~g} / 4184$ kJ (1000 kcal)‡ & & & & & $1 \cdot 07$ & $0.96,1.19$ & $1 \cdot 07$ & $0.96,1.19$ \\
\hline \multicolumn{9}{|l|}{ Added sugars (tsp/4184 kJ (1000 kcal)) } \\
\hline Q1 $(\leq 5 \cdot 3)$ & 85 & $20 \cdot 9$ & 153 & $25 \cdot 1$ & $1 \cdot 00$ & Ref. & $1 \cdot 00$ & Ref. \\
\hline Q2 (5.4-7.7) & 92 & $22 \cdot 7$ & 152 & $25 \cdot 0$ & $1 \cdot 14$ & $0.78,1.66$ & $1 \cdot 12$ & $0.76,1.65$ \\
\hline Q3 (7.8-10.9) & 118 & $29 \cdot 1$ & 153 & $25 \cdot 1$ & 1.42 & $0.98,2.05$ & $1 \cdot 39$ & $0.95,2.04$ \\
\hline Q4 $(\geq 11.0)$ & 111 & $27 \cdot 3$ & 151 & $24 \cdot 8$ & $1 \cdot 40$ & $0.97,2.03$ & $1 \cdot 33$ & $0.90,1.98$ \\
\hline$P_{\text {trend }}$ & & & & & & 0.06 & & 0.13 \\
\hline Per 6 tsp/4184 kJ (1000 kcal) & & & & & $1 \cdot 23$ & $1.03,1.46$ & $1 \cdot 20$ & $0.99,1.44$ \\
\hline \multicolumn{9}{|l|}{ Starch (g/4184 kJ (1000 kcal)) } \\
\hline Q1 $(\leq 42.7)$ & 122 & $30 \cdot 1$ & 156 & $25 \cdot 6$ & $1 \cdot 00$ & Ref. & $1 \cdot 00$ & Ref. \\
\hline Q2 (42.8-48.8) & 82 & $20 \cdot 2$ & 150 & $24 \cdot 6$ & 0.75 & $0.52,1.08$ & 0.75 & $0.52,1.09$ \\
\hline Q3 (48.9-54.9) & 105 & $25 \cdot 9$ & 151 & $24 \cdot 8$ & 0.89 & $0.63,1.27$ & 0.86 & $0.60,1.23$ \\
\hline Q4 $(\geq 55.0)$ & 97 & $23 \cdot 9$ & 152 & $25 \cdot 0$ & $0 \cdot 83$ & $0.58,1.18$ & $0 \cdot 84$ & $0.59,1.21$ \\
\hline$P_{\text {trend }}$ & & & & & & 0.39 & & 0.41 \\
\hline Per 10 g/4184 kJ (1000 kcal)‡ & & & & & 0.96 & $0.85,1.09$ & 0.97 & $0.85,1.09$ \\
\hline \multicolumn{9}{|l|}{ Total fibre (g/4184 kJ (1000 kcal)) } \\
\hline Q1 $(\leq 6.5)$ & 117 & $28 \cdot 8$ & 163 & $26 \cdot 8$ & $1 \cdot 00$ & Ref. & 1.00 & Ref. \\
\hline Q2 (6.6-8.3) & 104 & $25 \cdot 6$ & 142 & $23 \cdot 3$ & 0.92 & $0.64,1.32$ & 0.85 & $0.58,1.22$ \\
\hline Q3 (8.4-10.8) & 86 & $21 \cdot 2$ & 156 & $25 \cdot 6$ & 0.69 & $0.46,1.01$ & 0.64 & $0.43,0.94$ \\
\hline Q4 $(\geq 10.9)$ & 99 & $24 \cdot 4$ & 148 & $24 \cdot 3$ & $0 \cdot 88$ & $0.60,1.30$ & 0.79 & $0.53,1.17$ \\
\hline$P_{\text {trend }}$ & & & & & & 0.51 & & 0.27 \\
\hline Per 4 g/4184 kJ (1000 kcal)‡ & & & & & 0.92 & $0.79,1.06$ & 0.88 & $0.76,1.03$ \\
\hline \multicolumn{9}{|c|}{ Glycaemic load (units/4184 kJ (1000 kcal)) } \\
\hline Q1 $(\leq 50.8)$ & 83 & $20 \cdot 4$ & 155 & $25 \cdot 5$ & $1 \cdot 00$ & Ref. & $1 \cdot 00$ & Ref. \\
\hline Q2 (50.9-57.9) & 90 & $22 \cdot 2$ & 152 & $25 \cdot 0$ & $1 \cdot 10$ & $0.75,1.60$ & $1 \cdot 16$ & $0.79,1.71$ \\
\hline Q3 (58.0-64.9) & 125 & 30.8 & 150 & $24 \cdot 6$ & 1.53 & $1.07,2.21$ & 1.57 & $1 \cdot 09,2 \cdot 28$ \\
\hline Q4 $(\geq 65.0)$ & 108 & $26 \cdot 6$ & 152 & $25 \cdot 0$ & $1 \cdot 31$ & $0.91,1.90$ & $1 \cdot 35$ & $0.93,1.97$ \\
\hline$P_{\text {trend }}$ & & & & & & 0.06 & & 0.05 \\
\hline Per 10 units $/ 4184$ kJ (1000 kcal)‡ & & & & & $1 \cdot 17$ & $1.04,1.32$ & $1 \cdot 18$ & $1.04,1.33$ \\
\hline \multicolumn{9}{|l|}{ Glycaemic index (units) } \\
\hline Q1 $(\leq 49.9)$ & 96 & $23 \cdot 7$ & 155 & $25 \cdot 5$ & $1 \cdot 00$ & Ref. & $1 \cdot 00$ & Ref. \\
\hline Q2 (50.0-52.2) & 108 & $26 \cdot 6$ & 152 & $25 \cdot 0$ & $1 \cdot 10$ & $0.77,1.58$ & $1 \cdot 17$ & $0.81,1.69$ \\
\hline Q3 (52.3-54.8) & 103 & $25 \cdot 4$ & 156 & $25 \cdot 6$ & 0.97 & $0.68,1.40$ & 0.95 & $0.66,1.38$ \\
\hline Q4 ( $\geq 54.9)$ & 99 & $24 \cdot 4$ & 146 & $24 \cdot 0$ & 0.97 & $0.67,1.40$ & 1.03 & $0.70,1.50$ \\
\hline$P_{\text {trend }}$ & & & & & & 0.73 & & 0.86 \\
\hline Per 5 units $\ddagger$ & & & & & 0.99 & $0.84,1.17$ & 1.00 & $0.84,1.18$ \\
\hline
\end{tabular}

Q, quartile; Ref., referent values; tsp, teaspoon.

${ }^{*}$ Model 1 adjusted for age, education, region and total energy intake.

† Model 2 adjusted for age, education, region, total energy intake, parity, oral contraceptive use, menopause status, tubal ligation and family history of breast/ovarian cancer

(first-degree relative). For added sugars, model additionally adjusted for vegetable intake. For fibre, model additionally adjusted for alcohol consumption.

$\ddagger$ Increment used in continuous analyses based on the difference between 75 th and 25 th percentile of the control distribution, rounded to one significant digit. 
of insulin-like growth factor-1 (IGF-1) ${ }^{(7)}$. IGF-1 is recognised to play a critical role in promoting cell proliferation and inhibiting apoptosis $^{(45)}$. Higher circulating concentrations of IGF-1 were found in several cancer types such as prostate cancer and breast cancer ${ }^{(46)}$, but the evidence for ovarian cancer is inconsistent $^{(47-49)}$. Insulin and IGF-1 may also promote tumourigenesis through stimulating the production of sex hormones, especially androgens ${ }^{(50)}$, which has been implicated in the pathogenesis of ovarian cancer ${ }^{(51)}$. In addition, the acute glucose fluctuations were found to evoke oxidative stress $^{(52)}$, with subsequent oxidative DNA damage ${ }^{(53)}$, which was suggested to be involved in cancer development ${ }^{(53)}$.

Our results of a stronger association between sugars, GL and ovarian cancer among diabetic participants are biologically plausible, although we had limited power to detect a significant statistical interaction. Type II diabetic patients may suffer from long-term higher compensatory rise in insulin ${ }^{(8)}$, which in turn may increase cancer risk or growth via elevated $\mathrm{IGF}^{(7)}$. In addition, the cross-talk between the advanced glycation end products (AGE) and receptor for AGE system and oxidative stress are suggested to further increase the risk for cancers in diabetic patients ${ }^{(54)}$. Although our results can be chance findings and need to be replicated, given the high prevalence of diabetes among African-Americans and that ovarian cancer patients with diabetes exhibit poorer survival ${ }^{(55)}$, primary dietary interventions may be especially important for this vulnerable population.

A number of limitations of the current study should be considered. First, residual confounding is possible, even with adjusting for a wide array of covariates. Second, there is a concern that undetected ovarian cancer may influence dietary choices in the year before diagnosis, leading to an issue of reverse causation. However, this is unlikely for ovarian cancer, considering that the median pre-diagnostic symptom duration for invasive cases is 4 months ${ }^{(56)}$. In addition, we found no difference in any dietary variables under study between cases at early stages $v$. advanced stages, which argues against undetected disease influencing dietary choices. Third, recall bias is always possible in case-control studies, but the largely unknown relationship between sugary foods and ovarian cancer and, as a result, lack of awareness of this link in this population should minimise this problem. Fourth, self-reported carbohydrate intake may be subject to under-reporting ${ }^{(57)}$, and may limit our confidence to estimate the absolute amount of intake. However, FFQ have been shown to be a useful tool to rank individuals reliably based on their nutrient intakes, as in the present study $^{(38)}$. FFQ-measured dietary GI and GL have also been shown to be valid and reliable tools to investigate their relationships with disease risks ${ }^{(58,59)}$. Furthermore, participation rates in population-based epidemiological studies are declining; however, although this is of concern, we found that the distribution of main risk factors among AACES ovarian cancer cases and controls were similar to other studies among African-Americans ${ }^{(60)}$. Reduced response rates do not necessarily compromise the internal validity of the study, as representative samples could still be achieved with proper study designs ${ }^{(61)}$.

Major strengths of this study include the largest sample for this under-studied population and carefully collected information, which provides an unprecedented opportunity for studying the modifiable risk factors in this minority population.
In conclusion, the present study supports a detrimental role of a carbohydrate-rich diet in ovarian cancer. Considering the poorer survival among African-American ovarian cancer patients and no effective screening tool for ovarian cancer, prevention is especially important, particularly through dietary modification, which is relatively low cost and low risk compared with medical treatments. In addition, our findings suggest even greater risk from high carbohydrate intake among diabetics, although no significant statistical interaction was identified. As diabetes is more common among African-American women ${ }^{(62)}$, this finding may have important implications for ovarian cancer prevention in this population.

\section{Acknowledgements}

The authors acknowledge the AACES interviewers, Christine Bard, LaTonda Briggs, Whitney Franz (North Carolina) and Robin Gold (Detroit). The authors also acknowledge the individuals responsible for facilitating case ascertainment across the ten sites, including Jennifer Burczyk-Brown (Alabama); Rana Bayakly and Vicki Bennett (Georgia); the Louisiana Tumor Registry; Lisa Paddock and Manisha Narang (New Jersey); Diana Slone, Yingli Wolinsky, Steven Waggoner, Anne Heugel, Nancy Fusco, Kelly Ferguson, Peter Rose, Deb Strater, Taryn Ferber, Donna White, Lynn Borzi, Eric Jenison, Nairmeen Haller, Debbie Thomas, Vivian von Gruenigen, Michele McCarroll, Joyce Neading, John Geisler, Stephanie Smiddy, David Cohn, Michele Vaughan, Luis Vaccarello, Elayna Freese, James Pavelka, Pam Plummer, William Nahhas, Ellen Cato, John Moroney, Mark Wysong, Tonia Combs, Marci Bowling, Brandon Fletcher, Yingli Wolinsky (Ohio); Susan Bolick, Donna Acosta, Catherine Flanagan (South Carolina); Martin Whiteside (Tennessee) and Georgina Armstrong and the Texas Registry, Cancer Epidemiology and Surveillance Branch, Department of State Health Services.

The AACES study was funded by NCI (R01CA142081). Additional support was provided by Metropolitan Detroit Cancer Surveillance System with federal funds from the National Cancer Institute, National Institute of Health, Department of Health and Human Services, under contract no. HHSN261201000028C and the Epidemiology Research Core, supported in part by NCI Center grant (P30CA22453) to the Karmanos Cancer Institute, Wayne State University School of Medicine and NCI Center grant (P30CA072720) to the Rutgers Cancer Institute of New Jersey. The funders had no role in the design, analysis or writing of this article.

B. Q. and E. V. B.: study design and formulating the research question; P. G. M., A. J. A., J. S. B.-S., M. B., M. L. C., E. F., E. S. P., A. G. S., P. T., J. M. S. and E. V. B.: data acquisition; B. Q.: data analysis; B. Q. and E. V. B.: drafting the paper; B. Q.: primary responsibility for the final content; and all authors critically revised the paper and approved the final version of the manuscript.

The authors declare that there are no conflicts of interest.

\section{Supplementary material}

For supplementary material/s referred to in this article, please visit http://dx.doi.org/doi:10.1017/S0007114515004882 


\section{References}

1. American Cancer Society (2015) Cancer facts \& figures 2015. http://www.cancer.org/research/cancerfactsstatistics/ cancerfactsfigures2015/ (accessed April 2015).

2. Torre LA, Bray F, Siegel RL, et al. (2015) Global cancer statistics, 2012. CA Cancer J Clin 65, 87-108.

3. Berek JS, Friedlander ML \& Bast RC Jr (2010) Ovarian cancer. In Holland-Frei Cancer Medicine, 8th ed. pp. 1344-1375 [DW Kufe, EF Iii, JF Holland, RR Weichselbaum, RE Pollock, RC Jr Bast, WK Hong and WN Hait, editors]. Shelton, CT: People's Medical Publishing House.

4. Goff BA, Mandel L, Muntz HG, et al. (2000) Ovarian carcinoma diagnosis. Cancer 89, 2068-2075.

5. Chornokur G, Amankwah EK, Schildkraut JM, et al. (2013) Global ovarian cancer health disparities. Gynecol Oncol 129, 258-264.

6. World Cancer Research Fund/American Institute for Cancer Research (2014) Continuous Update Project Report. Food, Nutrition, Physical Activity, and the Prevention of Ovarian Cancer 2014. London: World Cancer Research Fund/ American Institute for Cancer Research.

7. Cohen DH \& LeRoith D (2012) Obesity, type 2 diabetes, and cancer: the insulin and IGF connection. Endocr Relat Cancer 19, F27-F45.

8. Kaaks R \& Lukanova A (2001) Energy balance and cancer: the role of insulin and insulin-like growth factor-I. Proc Nutr Soc 60, 91-106

9. Tzonou a, Hsieh CC, Polychronopoulou a, et al. (1993) Diet and ovarian cancer: a case-control study in Greece. Int J Cancer 55, 411-414.

10. Shu XO, Gao YT, Yuan JM, et al. (1989) Dietary factors and epithelial ovarian cancer. Br J Cancer 59, 92-96.

11. Risch Ha, Jain M, Marrett LD, et al. (1994) Dietary fat intake and risk of epithelial ovarian cancer. J Natl Cancer Inst 86, 1409-1415.

12. McCann SE, Freudenheim JL, Marshall JR, et al. (2003) Risk of human ovarian cancer is related to dietary intake of selected nutrients, phytochemicals and food groups. $J$ Nutr 133, 1937-1942.

13. Nagle CM, Kolahdooz F, Ibiebele TI, et al. (2011) Carbohydrate intake, glycemic load, glycemic index, and risk of ovarian cancer. Ann Oncol 22, 1332-1338.

14. Kushi LH, Mink PJ, Folsom AR, et al. (1999) Prospective study of diet and ovarian cancer. Am J Epidemiol 149, 21-31.

15. Silvera SN, Jain M, Howe GR, et al. (2007) Glycaemic index, glycaemic load and ovarian cancer risk: a prospective cohort study. Public Health Nutr 10, 1076-1081.

16. Bosetti C \& Negri E (2001) Diet and ovarian cancer risk: a case-control study in Italy. Int J Cancer 915, 911-915.

17. Bidoli E, La Vecchia C, Montella M, et al. (2002) Nutrient intake and ovarian cancer: an Italian case-control study. Cancer Causes Control 13, 255-261.

18. King MG, Olson SH, Paddock L, et al. (2013) Sugary food and beverage consumption and epithelial ovarian cancer risk: a population-based case-control study. BMC Cancer 13, 94 .

19. Tasevska N, Jiao L, Cross AJ, et al. (2012) Sugars in diet and risk of cancer in the NIH-AARP Diet and Health Study. Int J Cancer 130, 159-169.

20. Pelucchi C, La Vecchia C, Chatenoud L, et al. (2001) Dietary fibres and ovarian cancer risk. Eur J Cancer 37, 2235-2239.

21. Silvera SN, Jain M, Howe GR, et al. (2007) Dietary fiber intake and ovarian cancer risk: a prospective cohort study. Cancer Causes Control 18, 335-341.
22. Wolever TM, Jenkins DJ, Jenkins AL, et al. (1991) The glycemic index: methodology and clinical implications. Am J Clin Nutr $\mathbf{5 4}$, 846-854.

23. Salmeron J, Manson JE, Stampfer MJ, et al. (1997) Dietary fiber, glycemic load, and risk of non-insulin-dependent diabetes mellitus in women. JAMA 277, 472-477.

24. George SM, Mayne ST, Leitzmann MF, et al. (2009) Dietary glycemic index, glycemic load, and risk of cancer: a prospective cohort study. Am J Epidemiol 169, 462-472.

25. Augustin L \& Polesel J (2003) Dietary glycemic index, glycemic load and ovarian cancer risk: a case-control study in Italy. Ann Oncol 14, 78-84.

26. US Department of Agriculture, Agricultural Research Service, Beltsville Human Nutrition Research Center, Food Surveys Research Group and US Department of Health and Human Services, Centers for Disease Control and Prevention, National Center for Health Statistics (2015) What we eat in America, NHANES 2011-2012. http://www.ars.usda.gov/Services/docs. htm?docid=18349 (accessed May 2015).

27. Welsh JA, Sharma AJ, Grellinger L, et al. (2011) Consumption of added sugars is decreasing in the United States. Am J Clin Nutr 94, 726-734.

28. Lovejoy JC, Champagne CM, Smith SR, et al. (2001) Ethnic differences in dietary intakes, physical activity, and energy expenditure in middle-aged, premenopausal women: the Healthy Transitions Study. Am J Clin Nutr 74, 90-95.

29. Das SK, Sharma NK \& Zhang B (2015) Integrative network analysis reveals different pathophysiological mechanisms of insulin resistance among Caucasians and African Americans. BMC Med Genomics 8, 4

30. Haffner SM, Ralph DA, Saad MF, et al. (1996) Increased insulin resistance and insulin secretion in nondiabetic African-Americans and Hispanics compared with non-Hispanic Whites: the Insulin Resistance Atherosclerosis Study. Diabetes 45, 742-748.

31. Pearce CL, Templeman C, Rossing MA, et al. (2012) Association between endometriosis and risk of histological subtypes of ovarian cancer: a pooled analysis of case-control studies. Lancet Oncol 13, 385-394.

32. Yang HP, Trabert B, Murphy MA, et al. (2012) Ovarian cancer risk factors by histologic subtypes in the NIH-AARP diet and health study. Int J Cancer 131, 938-948.

33. Schildkraut JM, Alberg AJ, Bandera EV, et al. (2014) A multicenter population-based case-control study of ovarian cancer in African-American women: the African American Cancer Epidemiology Study (AACES). BMC Cancer 14, 688.

34. Boucher B, Cotterchio M, Kreiger N, et al. (2006) Validity and reliability of the Block98 food-frequency questionnaire in a sample of Canadian women. Public Health Nutr 9, 84-93.

35. Mares-Perlman JA, Klein B, Klein R, et al. (1993) A diet history questionnaire ranks nutrient intakes in middle-aged and older men and women similarly to multiple food records. $J$ Nutr 123, 489-501.

36. Foster-Powell K, Holt SH \& Brand-Miller JC (2002) International table of glycemic index and glycemic load values: 2002. Am J Clin Nutr 76, 5-56.

37. Willett WC, Howe GR \& Kushi LH (1997) Adjustment for total energy intake in epidemiologic studies. Am J Clin Nutr $\mathbf{6 5}$, 1220S-1228S.

38. Willett W (2012) Nutritional Epidemiology, 3rd ed. New York: Oxford University Press.

39. Collaborative Group on Epidemiological Studies of Ovarian Cancer (2012) Ovarian cancer and smoking: individual participant meta-analysis including 28,114 women with ovarian cancer from 51 epidemiological studies. Lancet Oncol 13, 946-956. 
40. Vos MB, Kimmons JE, Gillespie C, et al. (2008) Dietary fructose consumption among US children and adults: the Third National Health and Nutrition Examination Survey. Medscape J Med 10, 160.

41. Johnson RJ, Perez-Pozo SE, Sautin YY, et al. (2009) Hypothesis: could excessive fructose intake and uric acid cause type 2 diabetes? Endocr Rev 30, 96-116.

42. Arcidiacono B, Iiritano S, Nocera A, et al. (2012) Insulin resistance and cancer risk: an overview of the pathogenetic mechanisms. Exp Diabetes Res 2012, 789174.

43. Brown CC, Kipnis V, Freedman LS, et al. (1994) Energy adjustment methods for nutritional epidemiology: the effect of categorization. Am J Epidemiol 139, 323-338.

44. Salazar-Martinez E, Lazcano-Ponce EC, Gonzalez Lira-Lira G, et al. (2002) Nutritional determinants of epithelial ovarian cancer risk: a case-control study in Mexico. Oncology 63, 151-157.

45. Yu H \& Rohan T (2000) Role of the insulin-like growth factor family in cancer development and progression. J Natl Cancer Inst 92, 1472-1489.

46. Renehan AG, Zwahlen M, Minder C, et al. (2004) Insulin-like growth factor (IGF)-I, IGF binding protein-3, and cancer risk: systematic review and meta-regression analysis. Lancet $\mathbf{3 6 3}$, $1346-1353$.

47. Ose J, Fortner RT, Schock H, et al. (2015) Insulin-like growth factor I and risk of epithelial invasive ovarian cancer by tumour characteristics: results from the EPIC cohort. $\mathrm{Br} J$ Cancer 112, 162-166.

48. Lukanova A, Lundin E, Toniolo P, et al. (2002) Circulating levels of insulin-like growth factor-I and risk of ovarian cancer. Int J Cancer 101, 549-554.

49. Peeters PH, Lukanova A, Allen N, et al. (2007) Serum IGF-I, its major binding protein (IGFBP-3) and epithelial ovarian cancer risk: the European Prospective Investigation into Cancer and Nutrition (EPIC). Endocr Relat Cancer 14, 81-90.

50. Cara J (1994) Insulin-like growth factors, insulin-like growth factor binding proteins and ovarian androgen production. Horm Res 42, 49-54.

51. Risch HA (1998) Hormonal etiology of epithelial ovarian cancer, with a hypothesis concerning the role of androgens and progesterone. J Natl Cancer Inst 90, 1774-1786.
52. Monnier L, Mas E, Ginet C, et al. (2006) Activation of oxidative stress by acute glucose fluctuations compared with sustained chronic hyperglycemia in patients with type 2 diabetes. JAMA 295, 1681-1687.

53. Kidane D, Chae WJ, Czochor J, et al. (2014) Interplay between DNA repair and inflammation, and the link to cancer. Crit Rev Biochem Mol Biol 49, 116-139.

54. Abe R \& Yamagishi S (2008) AGE-RAGE system and carcinogenesis. Curr Pharm Des 14, 940-945.

55. Bakhru A, Buckanovich RJ \& Griggs JJ (2011) The impact of diabetes on survival in women with ovarian cancer. Gynecol Oncol 121, 106-111.

56. Vine MF, Ness RB, Calingaert B, et al. (2001) Types and duration of symptoms prior to diagnosis of invasive or borderline ovarian tumor. Gynecol Oncol 83, 466-471.

57. Poppitt SD, Swann D, Black AE, et al. (1998) Assessment of selective under-reporting of food intake by both obese and non-obese women in a metabolic facility. Int $J$ Obes Relat Metab Disord 22, 303-311.

58. Du H, van der A DL, van Bakel MM, et al. (2009) Reproducibility and relative validity of dietary glycaemic index and glycaemic load assessed by the food-frequency questionnaire used in the Dutch cohorts of the European Prospective Investigation into Cancer and Nutrition. Br J Nutr $\mathbf{1 0 2}$, 601-604.

59. Murakami K, Sasaki S, Takahashi Y, et al. (2008) Reproducibility and relative validity of dietary glycaemic index and load assessed with a self-administered diet-history questionnaire in Japanese adults. Br J Nutr 99, 639-648.

60. Moorman PG, Palmieri RT, Akushevich L, et al. (2009) Ovarian cancer risk factors in African-American and white women. $\mathrm{Am}$ J Epidemiol 170, 598-606.

61. Nelson DE, Powell-Griner E, Town M, et al. (2003) A comparison of national estimates from the National Health Interview Survey and the Behavioral Risk Factor Surveillance System. Am J Public Health 93, 1335-1341.

62. Centers for Disease Control and Prevention (2014) National Diabetes Statistics Report: Estimates of Diabetes and Its Burden in the United States, 2014. Atlanta, GA: US Department of Health and Human Services. 